\title{
A Retrospective Analysis on the Pharmacological Management of Irritable Bowel Syndrome
}

\author{
Subair MA', Sharad Chand ${ }^{1}$, Nandakumar UP1', Ganaraj Kulamarva², Juno J Joel',* \\ 'Department of Pharmacy Practice, NITTE Gulabi Shetty Memorial Institute of Pharmaceutical Sciences (NGSMIPS), NITTE (Deemed to be University), Deralakatte, \\ Mangaluru, Karnataka, INDIA. \\ ²Department of Gastroenterology, Justice KS Hegde Charitable Hospital, NITTE (Deemed to be University), Mangaluru, Karnataka, INDIA.
}

\begin{abstract}
Objectives: To analyze the pattern of drugs prescribed to treat irritable bowel syndrome among patients admitted in a tertiary care teaching hospital. Materials and Methods: A retrospective study was carried out among 120 inpatients of the general medicine department for a period of eight months from August 2019 to April 2020. The data of the patients admitted to the hospital over a period of five years was collected from the medical records department in a specially designed data collection form. The prescription pattern of the drugs used in the management of irritable bowel syndrome was analyzed using descriptive statistics. Results: Among 120 patients, $n=68$ were diagnosed with inflammatory bowel syndrome (IBS)-D, $n=30$ with IBS-M and $n=22$ diagnosed with IBS-C. The occurrence of irritable bowel syndrome was higher in males $(55 \%)$ than in females (45\%). The most common clinical presentation was found to be abdominal pain, reported among $63.33 \%$ of the total patients. Probiotics were the most widely prescribed medications $n=73(14.39 \%)$,
\end{abstract}

followed by pantoprazole $n=65$ (12.82\%). Conclusion: In the study, movement modulators followed by adjunctive gastrointestinal agents, psychoactive substances and antibiotics were commonly prescribed for the management of irritable bowel syndrome.

Key words: IBS, Pharmacotherapy, Abdominal pain, Colonoscopy, Probiotics.

\section{Correspondence}

Dr. Juno J Joel,

Assistant Professor, Department of Pharmacy Practice, NITTE Gulabi Shetty Memorial Institute of Pharmaceutical Sciences (NGSMIPS), NITTE (Deemed to be University), Deralakatte, Mangaluru-575018, Karnataka, INDIA.

Email: junojoel@nitte.edu.in

DOI: 10.5530/jyp.2021.13.38

\section{INTRODUCTION}

Irritable Bowel Syndrome (IBS) is a mix of abdominal discomfort or pain and trouble with altered bowel habits; either diarrhea or constipation. IBS is one among the many diseases which drastically affect the quality of life of patients. ${ }^{1}$ The etiology of IBS is still unclear, but psychological, social and biological factors may play a role in the progression of this disease. ${ }^{2}$ The availability of limited medications in the treatment of IBS has resulted in several trends in its treatment. Drug utilization in IBS differs with geography, prescriber's preferences and economic considerations due to the lack of standard guidelines to direct therapy. A physician's prescription is based basically on his level of knowledge, experience, and the perspective towards the disease as well as the availability of resources. ${ }^{3,4}$ An evaluation of the trend in the prescribing pattern helps us in understanding the practice being followed in any institution. These studies may contribute in effective hospital formulary preparation, designing of the essential drugs list, as well as in framing guidelines for an institution. In several instances, the hospital may not follow the global trends; in such cases, the prescribing pattern analysis is an essential element to determine the course and outcome of the prescribed therapies. ${ }^{5-8}$ It also promotes the rational use of drugs and enables us to monitor the therapy to minimize or to prevent drug-related problems. Prescription pattern studies are the clinical feedback for the prescribers, dispensers and for the general public on the appropriateness of the usage of drugs. ${ }^{9-11}$ With the background of unsolicited therapy of IBS and the need for prescription pattern studies, we aimed to analyze the pattern of prescription of drugs used for the treatment of IBS.

\section{MATERIALS AND METHODS}

A retrospective observational study of eight months was conducted by collecting the data from the medical records department of a multispecialty teaching hospital in Dakshina Kannada district of South India. Research ethics committee approval was obtained before the initiation of the study. The data of patients admitted to the hospital over a period of five years was collected. A total of 120 patients of either gender, aged above 18 years, diagnosed with IBS and those who received treatment in the department of general medicine were enrolled in the study. The cases with incomplete or missing information were excluded. A data collection form was designed to obtain the socio-demographics, disease-related and therapy-related details of the patients. All relevant information was collected from the concerned patient case files including treatment charts. The different types of IBS, corresponding signs and symptoms as well as diagnoses were studied. Based on the predominance of symptoms, IBS was classified into three major categories, namely IBS-D (Diarrhoea predominant), IBS-C (Constipation predominant) and IBS-M (Mixed bowel habits). Details of the therapy such as the name of the drug, its dosage form, frequency, route of administration, duration of treatment, length of hospital stay, and the number of drugs per prescription were recorded in the data collection sheet. Descriptive statistical analysis was performed to summarize the outcomes at the end of the study.

\section{RESULTS}

\section{Demographic Characteristics of the Study Population}

A total of 120 patients were enrolled in the study. Majority were males, $n=66(55 \%)$ followed by females, $n=54$ (45\%). A majority of the patients belong to the age group of $21-40$ years $n=56$ (46.66\%), followed by the age group $41-60$ years $n=45(37.5 \%)$, and the age group $61-80$ years $n=17$ $(14.16 \%)$. Only $n=2(1.66 \%)$ were found below 20 years of age. 


\section{Distribution of Patients Based on the Types of IBS and} their Clinical Presentations

In our study, IBS-D was the most frequently diagnosed $n=68(58.7 \%)$, followed by IBS-M $n=30$ (25.0\%) patients and IBS-C $n=22(18.3 \%)$ patients. The most common clinical presentations were found to be abdominal pain, reported among $63.33 \%$ of the total population, followed by loose stools among $37.50 \%$. Bloating, hard stools and mucus in stools were reported among $22.5 \%, 20 \%$ and $15.5 \%$ of the total subjects, respectively. Weight loss was reported only among $15 \%$. The clinical symptoms of the patients had a significant correlation with the diagnosis. $90 \%$ of patients with confirmed IBS-D complained of diarrhea and hard stools were reported in $100 \%$ IBS-C patients. In this study, the frequency of bowel movements was increased up to 5-6 times per day in $n=28(41.17 \%)$ patients, $3-4$ times among $n=38$ (55.87\%) subjects and only $n=2$ (3.94\%) documented episodes more than 7 times.

\section{Distribution of Patients Based on the Diagnostic Tests Performed}

Blood tests were performed in all the patients. However, stool examination was performed only among $5 \%$ of the study population, $n=6$. Out of 120 subjects, majority $n=65$ (54.16\%) were diagnosed with an ultrasonography abdomen, followed by colonoscopy among $n=55$ $(45.83 \%)$ and only $n=6(5 \%)$ were subjected to a computed tomography scan.

\section{Distribution of Various Drugs Prescribed Among the Study Population}

A total of $n=507$ medications were prescribed among 120 patients with an average of 4.2 drugs per prescription. Probiotics were the most widely prescribed medications $n=73$ ( $14.39 \%$ ), followed by pantoprazole $n=65$ (12.82\%). The detailed data is summarized in Table 1 .

\section{DISCUSSION}

The present study was conducted to analyses the pharmacotherapy in the management of IBS. In this study, the mean age of the patients was found to be 42.90 years. The results were found to be comparable with the study conducted by Brun-Strang et al. in which the mean age of the patients were $53.9 \pm 14.9$ years. ${ }^{12}$ The study concluded on the high prevalence of IBS among males (55.0\%). This aspect of the result was found to be in contradiction with the results of Faresjö A et al. in which the statistics of IBS occurrence among females (72.3\%) outnumbered the males. ${ }^{13}$ As explained in the results section, 68 patients were diagnosed with IBS-D, 30 with IBS-M and 22 with IBS-C. The results were not in agreement with the study conducted by Rusu $\mathrm{F}$ et al. wherein $60 \%$ of the total patients were diagnosed with IBS-C, $34 \%$ with IBS-D and only $6 \%$ had IBS-mixed. ${ }^{14}$ On evaluation, the most common clinical presentation among patients was reported to be abdominal pain (63.33\%) and this was similar to the study results of Brun-Strang et al. as the main symptoms presented by the patients were abdominal pain (72\%) followed by bloating (58\%). However, the latter was reported only amongst $22.5 \%$ of the subjects. ${ }^{12}$ In contradiction to the study conducted by Hillila MT et al. blood tests were conducted among $100 \%$ of the patients whereas comparable observation was made on the number of colonoscopies performed. ${ }^{15}$ On analyzing the pattern of prescription, the study performed by Rusu $\mathrm{F}$ et al. were in tandem with the results of this study. ${ }^{14}$

\section{CONCLUSION}

The study documented a higher occurrence of IBS among males and the mean age of the study population was found to be 42.90 years. The
Table 1: Distribution of drugs prescribed among the study population.

\begin{tabular}{|c|c|c|}
\hline Generic name (In combination with) & $\begin{array}{c}\text { No. of } \\
\text { prescriptions }\end{array}$ & $\begin{array}{l}\text { Percentage } \\
\text { (\%) }\end{array}$ \\
\hline Probiotics & 73 & 14.39 \\
\hline Pantoprazole & 65 & 12.82 \\
\hline $\begin{array}{c}\text { Chlordiazapoxide+clinidium }+ \text { mebiv } \\
\text { erine }\end{array}$ & 50 & 9.86 \\
\hline Clinidium+chlordiazapoxide & 38 & 7.49 \\
\hline Rifaximin & 36 & 7.10 \\
\hline Mebiverine+chlordiazapoxide & 21 & 4.14 \\
\hline Multivitamins & 17 & 3.35 \\
\hline Tramadol+Paracetamol & 17 & 3.35 \\
\hline Pantoprazole+ Domperidone & 15 & 2.95 \\
\hline Rabeprazole & 13 & 2.56 \\
\hline Pinaverium bromide & 13 & 2.56 \\
\hline Ramocetrone & 10 & 1.97 \\
\hline Lactilol monohydrate & 9 & 1.77 \\
\hline Alprazolam & 8 & 1.57 \\
\hline Metformin & 8 & 1.57 \\
\hline Hyocyamine sulphate & 8 & 1.57 \\
\hline Isapgula+Lactilol monohydrate & 7 & 1.38 \\
\hline Cefixime & 7 & 1.38 \\
\hline Amoxicillin & 7 & 1.38 \\
\hline Iron and folic acid supplements & 7 & 1.38 \\
\hline Sertaline & 6 & 1.18 \\
\hline Ornidazole & 6 & 1.18 \\
\hline Butylscopulamine & 6 & 1.18 \\
\hline Ciprofloxacin & 6 & 1.18 \\
\hline Telmisartan & 6 & 1.18 \\
\hline Amitriptyline & 5 & 0.98 \\
\hline Amlodipine & 4 & 0.79 \\
\hline Atorvastatin & 4 & 0.79 \\
\hline Albendazole & 4 & 0.79 \\
\hline Sucralfate & 4 & 0.79 \\
\hline Lorazepam & 4 & 0.79 \\
\hline Calcium supplements & 3 & 0.60 \\
\hline Others & 20 & 3.95 \\
\hline
\end{tabular}

most common clinical presentations were found to be abdominal pain, loose stools, and bloating. Blood tests were performed in almost all patients and medication was prescribed to either increase or decrease the gastric transit time. The average number of drugs per prescription was found to be 4.2. This study thus, provides a classic frame of trends in the prescribing pattern of drugs for the management of irritable bowel syndrome.

\section{ACKNOWLEDGEMENT}

We authors would like to thank Justice K.S. Hegde Charitable Hospital for their support during the research work.

\section{CONFLICT OF INTEREST}

The authors declare that there is no conflict of interest.

\section{ABBREVIATIONS}

IBS: Irritable Bowel Syndrome; IBS-D: Irritable Bowel Syndromediarrhea; IBS-C: Irritable Bowel Syndrome-Constipation; IBS-M: Irritable Bowel Syndrome-Mixed.

\section{REFERENCES}

1. Fabel PH, Shealy KM. Diarrhea, Constipation, and Irritable bowel syndrome: 
Pharmacotherapy A pathophysiologic approach. $9^{\text {th }}$-edition. New York: Mc Graw Hill Education; 2014;531-46.

2. Cann PA, Read NW, Holdsworth CD, Barends D. Role of loperamide and placebo in management of irritable bowel syndrome (IBS). Int J Digestive Dis Sci. 1984;29(3):239-47.

3. Mayer EA, Naliboff BD, Chang L, Coutinho SV. V. Stress and irritable bowel syndrome. Am J Physiol Gastrointest. 2001;280(4):G519-24.

4. Shirpa J, Zafar K, Prerna U, Kumar A. Assesment of prescription pattern in a private teaching hospital in India. Int J Pharma Sci. 2012;3(3):219-22.

5. Chandran BK, Vaddakan K, Altaf M, Shetty V, Chand S, Vijayan A, et al. A retrospective study on prospective usage pattern of analgesics in orthopaedics department of a tertiary care hospital. IJSTR. 2020;9(03):1207-11.

6. Al-Jabri MM, Shastry CS, Chand S. Assessment of drug utilization pattern in chronic kidney disease patients in a tertiary care hospital based on who core drug use indicators. JGPT. 2019;11(9):1-9.

7. Gouda V, Shastry CS, Mateti UV, Subrahmanya C, Chand S. Study on steroid utilization patterns in general medicine department. Research J Pharm and Tech. 2019;12(10):4771-6.

8. Mohammed HAR, Babu N, Chand S, Nandakumar UP, Bharathraj KC. Study on prescription pattern for osteoarthritis in a tertiary care teaching hospital: A retrospective study. Biomedicine. 2020;40(03):353-6.
9. Mehaneesha K, Rishab P, Seetharam SS, Mathias L, Chand S, Nandakumar UP, et al. A retrospective study on drug utilization pattern in management of rheumatoid arthritis. Research J Pharm and Tech. 2020;13(11):5263-6.

10. Chacko CS, Nandakumar UP, Chand S, et al. Prescribing pattern among out patients of department of obstetrics and gynaecology in a tertiary care hospital. Plant Archives. 2020;20(Spl.02):2249-51.

11. Voora L, Sah SK, Bhandari R, Shastry CS, Chand S, Rawal KB, et al. Doctor of pharmacy: Boon for healthcare system. Drug Invention Today. 2020;14(1):153-8.

12. Brun-Strang C, Dapoigny M, Lafuma A, Wainsten JP, Fagnani F. Irritable bowel syndrome in France: quality of life, medical management, and costs: The Encoli study. Euro J of Gastroenterol and Hepatol. 2007;19(12):1097-103.

13. Faresjo A, Grodzinsky E, Johansson S, Wallander MA, Faresjo T, Timpka T. Selfreported use of pharmaceuticals among patients with irritable bowel syndrome in primary care. J Manag Care Spec Pharm. 2008;14(9):870-7.

14. Rusu F, Dumitraşcu DL. Four years follow-up of patients with irritable bowel syndrome. Romanian Journal of Internal Medicine. 2015;53(1):65-74.

15. Hillilä MT, Siivola MT, Färkkilä MA. Comorbidity and use of health-care services among irritable bowel syndrome sufferers. Sc Jour of Gastroenterol. 2007;42(7):799-806.

Article History: Submission Date : 30-03-2021; Revised Date : 16-04-2021; Acceptance Date : 04-05-2021.

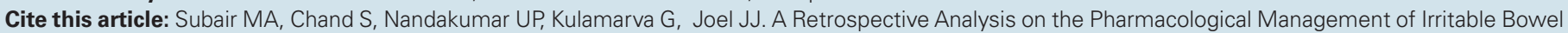
Syndrome. J Young Pharm. 2021;13(2):186-8. 